\title{
DUCTILE DAMAGE MODEL OF AN ALLUMINUM ALLOY: EXPERIMENTAL AND NUMERICAL VALIDATION ON A PUNCH TEST
}

\author{
MARCO NICOLA MASTRONE, LORENZO FRACCAROLI \& FRANCO CONCLI \\ Free University of Bolzano/Bozen, Faculty of Science and Technology, Bolzano, Italy.
}

\begin{abstract}
The correct prediction of ductile fracture of mechanical components requires the knowledge of physical quantities that are in the plastic field. This region is characterized by non-linearities, and the classical yield criteria cannot be applied since they work only in the elastic field. It has been observed that parameters such as stress triaxiality and plastic strain play a determinant role in failure mechanisms. Thanks to simulation software, it is possible to implement the virtual models capable of calculating these parameters numerically by solving partial differential equations. These parameters can then be used to describe the fracture locus of a material that, in turn, allows to predict failure of a component. In this work, the Rice and Tracey damage model was calibrated for an aluminum alloy and validated on a punch test exploiting Finite Element Analysis. Good agreement between experimental observations and numerical results was obtained, demonstrating the capability of the considered model to predict failure on a real test case.
\end{abstract}

Keywords: Ductile Damage Models, FEA, Fracture Locus, Punch test, Rice and Tracey.

\section{INTRODUCTION}

Several often significant and inevitable plastic deformation must be considered in mechanical design. Pressure vessels, for example, must be designed with materials that can dissipate energy and carry large deformations. Ductile fracture in metals has been studied since the '50s. Starting from the assumptions of brittle fracture mechanics, macroscopic concepts as crack opening displacement were exploited to identify a characteristic parameter for ductile fracture. In parallel, ductile fracture was also studied microscopically to better understand the micro mechanism of failure, which was observed to be dependent on micro voids formation. These voids grow under external stresses until a critical dimension that determines the generation of cracks. In ductile fracture, the strain at failure (i.e. the maximum deformation until the ultimate strength) is a fundamental parameter that is strongly influenced by the stress state. Indeed, multi-axial tensile stress state reduce the strain at failure with respect to the value measured in a monoaxial tensile test, while a hydrostatic compressive state raises the maximum deformation of the material. On this basis, several models have been proposed for ductile materials in presence of porosity. The constitutive variable of these models is the damage, which accounts for the progressive reduction of the material to undergo loads. These models represent a fundamental tool to foresee the material response under large plastic deformations.

In literature, simple models, in which failure is function only of the critical equivalent plastic strain, as well as more complex formulations, in which the fracture is function of 
several other parameters, can be found. The triaxiality was found to decrease the ductility of materials by decreasing the plastic strain exponentially [1-4]. Successive studies by Bao and Wierzbicki [5] and Wierzbicki et al. [6] identified different regions on the triaxiality-plastic strain plot, which can be described by different analytical equations corresponding to different fracture generation. Other authors [7-9] performed experimental studies on several materials in various triaxiality ranges to understand the influence of this parameter on failure mechanisms. Further studies [10] highlighted that under non-proportional loads, non-linear models should be used to correctly describe fracture of ductile materials. Non-linear models were developed by [11-13] to account for time-varying non-proportional loads. Benzerga et al. [14] suggest that the final state of stress is not sufficient to describe the fracture strain and that the entire loading path should be considered. Another parameter, namely the Lode parameter, is considered in more complex damage model formulations [15-18]. These models have been applied in simulation software to calibrate the fracture locus of materials [19] and to study the structures' behavior in the plastic field numerically [20, 21].

In this paper, the fracture locus describing the failure of an aluminum alloy was found with a combined experimental-numerical procedure. The model was initially calibrated based on three sample geometries, whose results were presented in a previous work by the authors [22]. The present paper is an extension of the previous analysis, and is focused on its application and validation using a punch test as reference case.

\section{MATERIALS AND METHODS}

To perform the experimental tests, an MTS Criterion 45 machine (maximum applicable load: $100 \mathrm{kN}$ ) was used. Quasi-static tensile tests on different notched specimens allowed to obtain the force-displacement relationship necessary for the material characterization. A round smooth sample and two differently notched samples were used for the experimental investigations (Fig. 1).

The open-source environment Salome_Meca was used to simulate the tensile tests and to characterize the material. This allowed to find the stress-strain values that provided as input in the material properties of the finite element model give as output as force-displacement curve comparable with the experimental one. Open-source codes offer some advantages with respect to commercial software. First, there are no license costs. Furthermore, the high customization possibilities of these tools allow to develop user-specified utilities to study a particular prob-

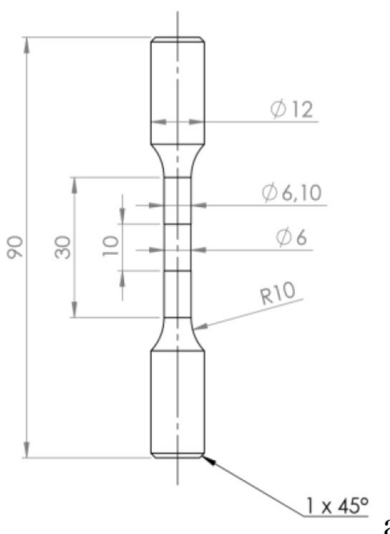

a)

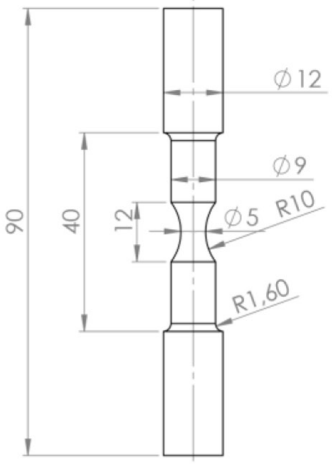

b)

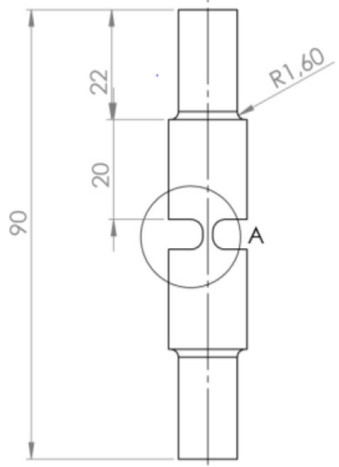

) c)

Figure 1: a-c) Tested samples geometry. 
lem without limitations on the source code manipulation. The main drawback is related to the learning process, which can take some time to understand how the code works.

The material was characterized with the Voce formulation, which enables the description of the true stress-strain relation to be inputted in the software with four parameters:

$$
\sigma_{\text {voce }}=A+B \cdot\left(1-e^{-C \cdot \varepsilon_{p l}}\right)+D \cdot \varepsilon_{p l}
$$

While the yielding stress $A$ can be found from the experimental traction curve, the other constants $B, C$, and $D$ must be calibrated with an iterative procedure until the Voce curve fits the true curve accurately (Fig. 2) and, at the same time, the force-displacement (F-s) curves (FEA and experimental) of all the three specimens overlap well (Fig. 3). The plastic deformation $\varepsilon_{p l}$ in the Voce equation is a datum that can be obtained from the experimental tests as the difference between the total and the elastic deformation.

In Table 1, the Voce constants that reproduce the true curve are reported.

Over the last decade, different analytical models have been formulated to describe the fracture locus. Depending on specific material characteristics such as the ductility, a certain model can be considered more appropriate and/or accurate to predict the failure of the material.

Rice and Tracey [2] introduced an exponential decreasing function between the triaxiality $(\eta)$ and the equivalent plastic strain at failure $\left(\varepsilon_{\text {peeq }}\right)$.

$$
\varepsilon_{\text {peeq }}=\left[D_{1}+D_{2} \cdot \exp \left(D_{3} \cdot \eta\right)\right]
$$

where $\eta$ is calculated dividing the mean stress by the von Mises stress.

Subsequent studies by Johnson and Cook [4] demonstrated that additional parameters (namely strain rate $\varepsilon_{p l}$ and temperature $T$ ) play a role in the formulation of the fracture locus.

Table 1: Voce constants.

\begin{tabular}{llll}
\hline $\mathbf{A}[\mathbf{M P a}]$ & $\mathbf{B}[\mathbf{M P a}]$ & $\mathbf{C}[-]$ & $\mathbf{D}[\mathbf{M P a}]$ \\
\hline 75 & 90 & 75 & 70 \\
\hline
\end{tabular}

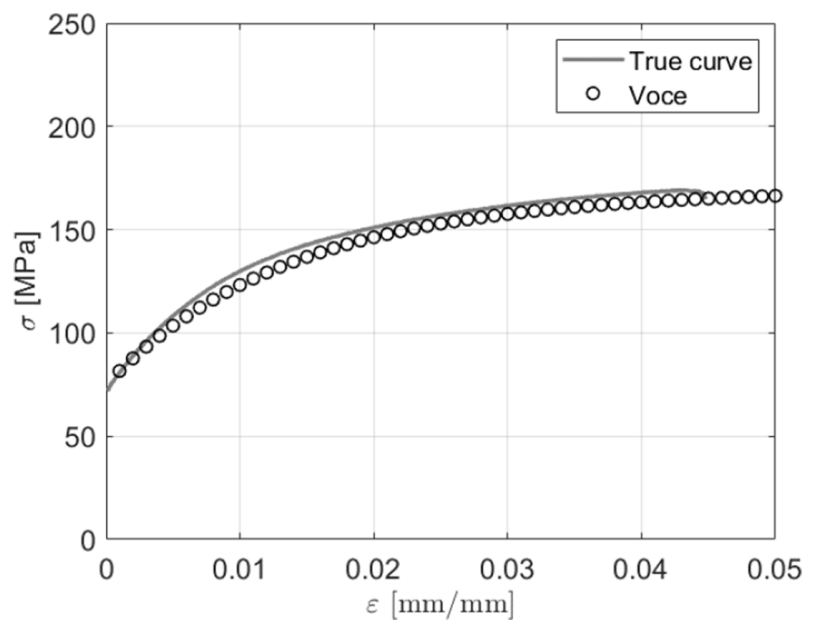

Figure 2: Voce approximation to the true curve. 

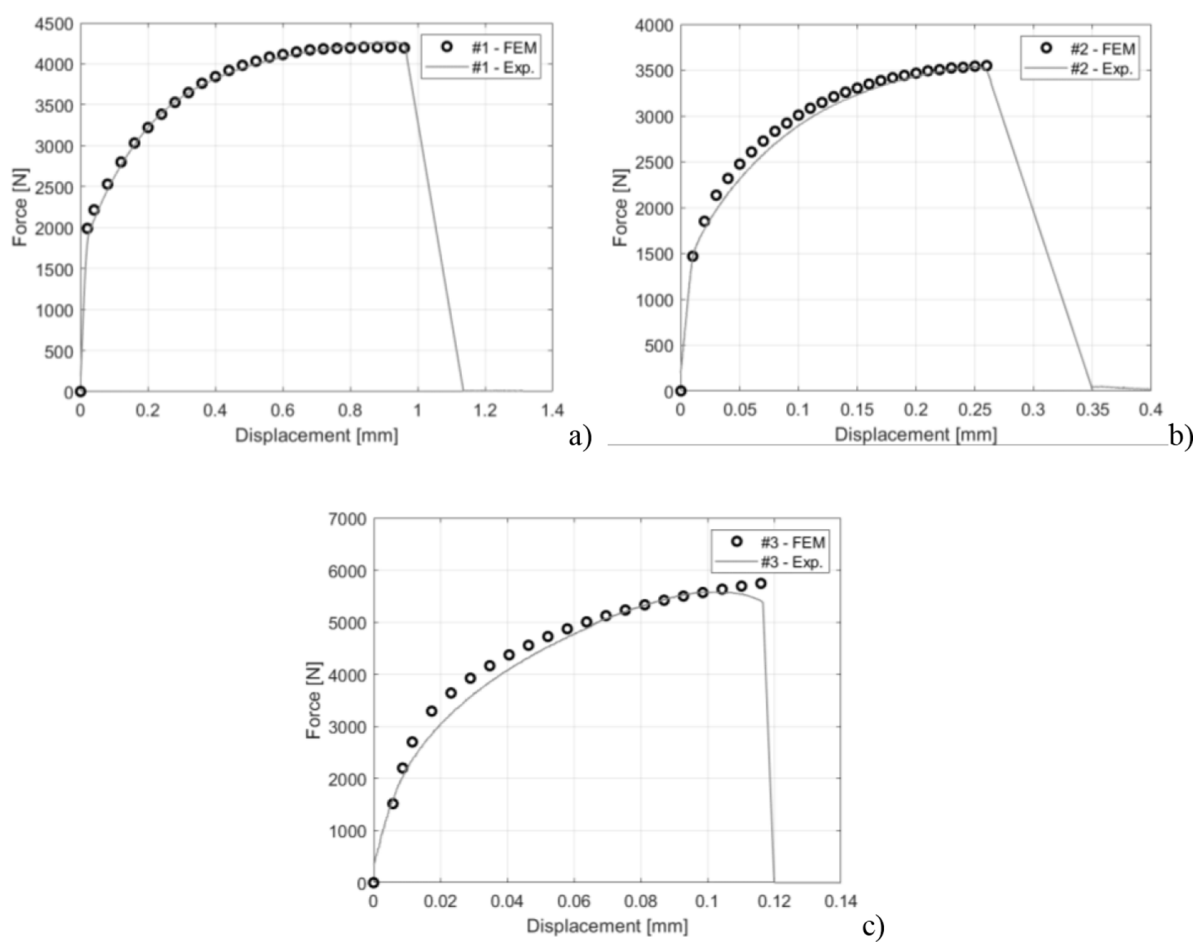

Figure 3: a-c) F-s curves for the three specimens.

$$
\varepsilon_{f}=\left[D_{1}+D_{2} \cdot \exp \left(D_{3} \cdot \eta\right)\right] \cdot\left[1+D_{4} \cdot \ln \left(\dot{\varepsilon}_{p l}\right)\right] \cdot\left[1+D_{5} \cdot T\right]
$$

Being $D_{1}, D_{2}, D_{3}, D_{4}$, and $D_{5}$ constants dependent on the material.

Further analyses by Wierzbicki et al. [5, 6, 23] highlighted that, depending on the triaxiality value, fracture occurs due to different physical phenomena. Indeed, for negative values of triaxiality, failure originates from shearing, while for positive values from void formation mechanism. In the middle range, the two above-mentioned phenomena contribute to failure concurrently (Fig. 4).

Xue and Wierzbicki [24] formulated a mathematical description that considers a function dependent on three parameters, namely the triaxiality, the equivalent plastic strain and the Lode parameter. When this function reaches the value of 1 , failure occurs:

$$
\int_{0}^{\varepsilon_{f}} \frac{d \varepsilon}{F(\eta, \xi)}=1
$$

The Lode parameter $\xi$ can be calculated as follows:

$$
\xi=\frac{27}{2} \frac{J_{3}}{\sigma_{v M}^{3}}
$$

In this equation, $\mathrm{J}_{3}$ is the third invariant of the deviatoric stress tensor and $\sigma_{v M}$ is the equivalent Von Mises stress. 


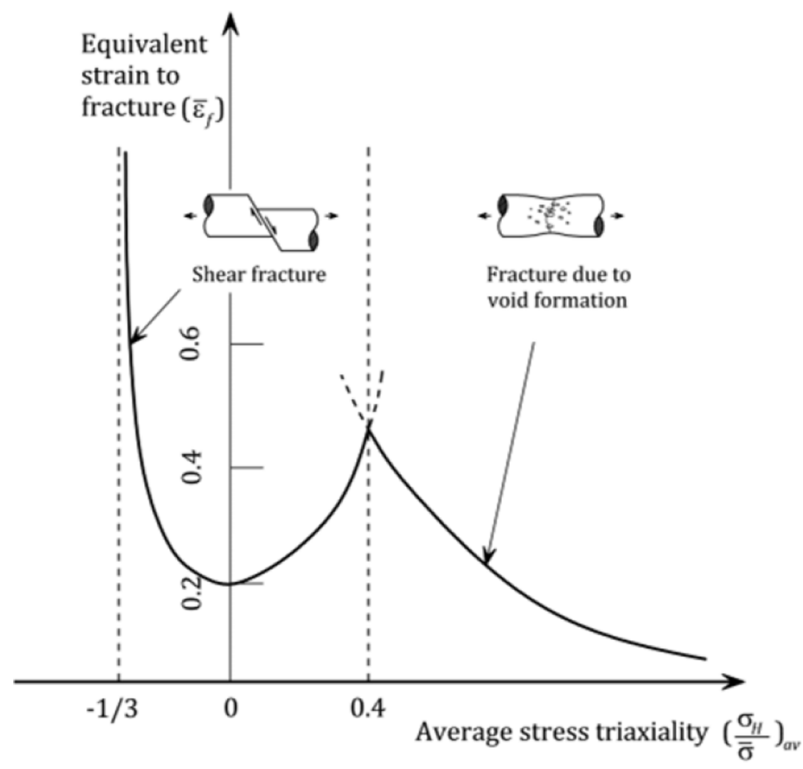

Figure 4: Fracture mechanisms in different regions on the triaxiality-equivalent plastic strain plot (source:[19]).

In the current analysis, the triaxiality of the tested specimens exhibited values above 0.33. For this reason, a decreasing exponential model was considered adequate, and, therefore, the Rice and Tracey formulation was used to tune the fracture locus.

\section{RESULTS}

\subsection{Fracture Locus Calibration}

In order to tune the fracture locus, a combined experimental-numerical approach was required before applying it to the punch test. Given the geometry of the specimens, it was possible to take advantage of some modeling simplifications that allowed to diminish the number of computational cells and speed up the numerical solution. In particular, two specimens were modeled with axis-symmetric consideration since they are solids of revolution. The mesh was made by quadrilateral elements only. For the other sample, it was possible to exploit standard symmetry boundary conditions. Hexahedral elements were used in the most critical region, while tetrahedrons were used in the upper region of the geometry, where no plastic deformation occurs (Fig. 5).

A non-linear solver with incremental load was used to ensure the convergence of the solution. The simulations were run on a Deploy LXD Compute Node (INTEL Xeon® E-2680, 3.5 GHz) with Code_Aster 2018. In order to simulate the tensile tests, the boundary conditions as reported in Fig. 6 were specified. On the upper face, a vertical displacement was applied: this corresponds to the value that caused the fracture of the samples in the experimental tests. The partial differential equations are solved iteratively by the solver. In Figs. 6-8, the contours of $\eta$ and $\varepsilon_{\text {peeq }}$ at the maximum deformation are reported.

In Table 2, the numerical values of $\eta$ and $\varepsilon_{\text {peeq }}$ for each of the three samples are reported. 


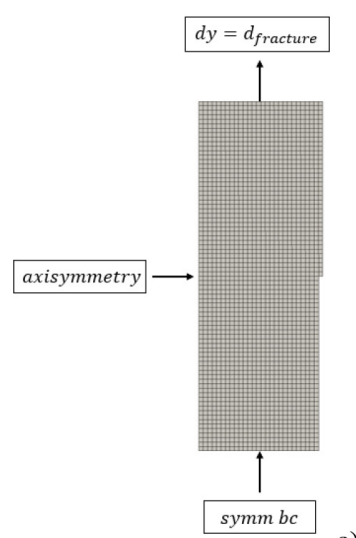

a)

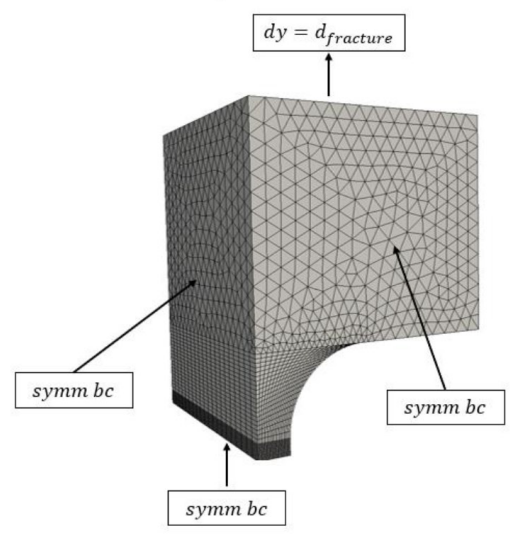

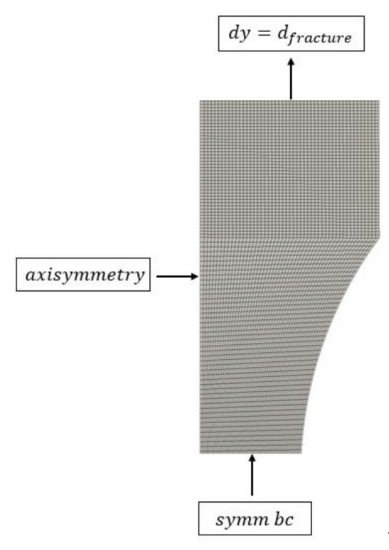

b)

c)

Figure 5: Numerical mesh and boundary conditions of the three specimens.
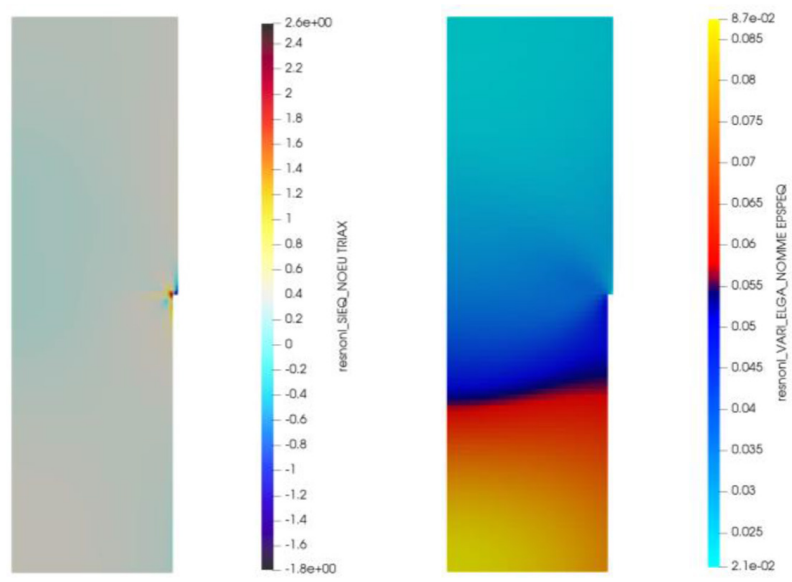

Figure6: $\eta$ and $\varepsilon_{\text {peeq }}$ contours at failure (first specimen). 

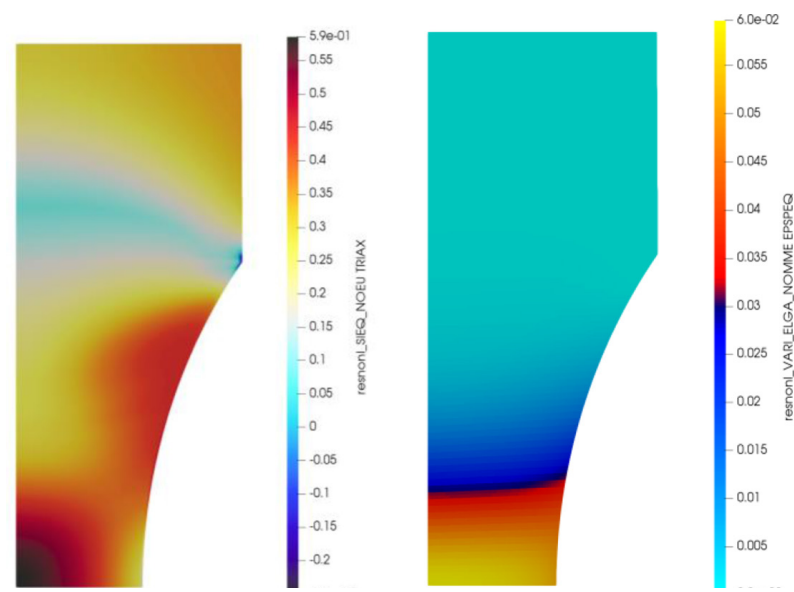

Figure 7: $\eta$ and $\varepsilon_{\text {peeq }}$ contours at failure (second specimen).
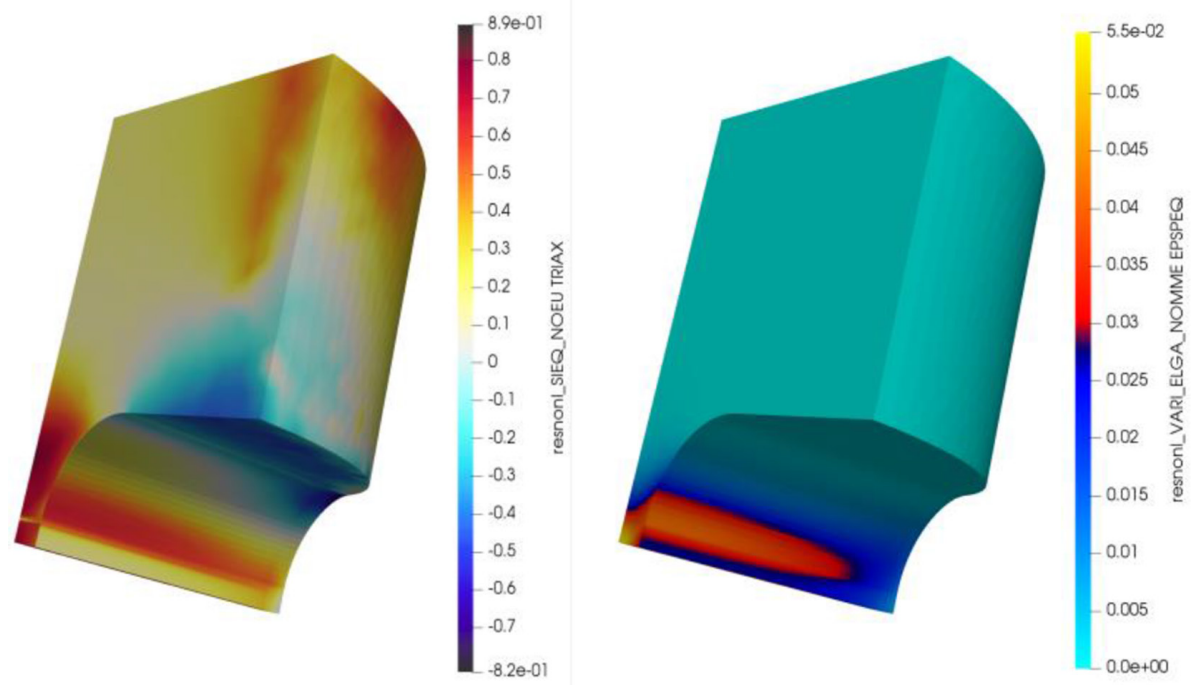

Figure 8: $\eta$ and $\varepsilon_{\text {peeq }}$ contours at failure (third specimen).

Table 2: Triaxiality and equivalent plastic strain of the three samples.

\begin{tabular}{lll}
\hline Sample & $\eta$ & $\varepsilon_{\text {peeq }}$ \\
\hline$\# 1$ & 0.39 & 0.087 \\
$\# 2$ & 0.59 & 0.059 \\
$\# 3$ & 0.70 & 0.055 \\
\hline
\end{tabular}


The Rice and Tracey damage model can be defined by Equation (6) obtained from the interpolation of triaxiality and equivalent plastic strain as follows:

$$
\varepsilon_{\text {peeq }}=-0.0021+0.1573 \cdot \exp (-1.5040 \cdot \eta)
$$

\subsection{Punch Test}

A punch test was performed to validate the calibrated parameters. A thin lamina of the same material was object of the test. The punch was made of hardened steel. A die was placed below the lamina in order to support it around the perimeter of the hole. The punch test setup is illustrated in Fig. 9.

In order to apply the calibrated damage model, punch tests with different loads were reproduced in the simulation software. The lamina was meshed with hexahedral cells, while the punch and the die were meshed with tetrahedrons. A vertical load is assigned to the punch and contact regions are defined between the punch and the lamina to avoid penetration issues. The results are saved each time step to monitor how the triaxiality and the plastic strain evolve during the simulation. In accordance to experiments, failure occurs with a load of

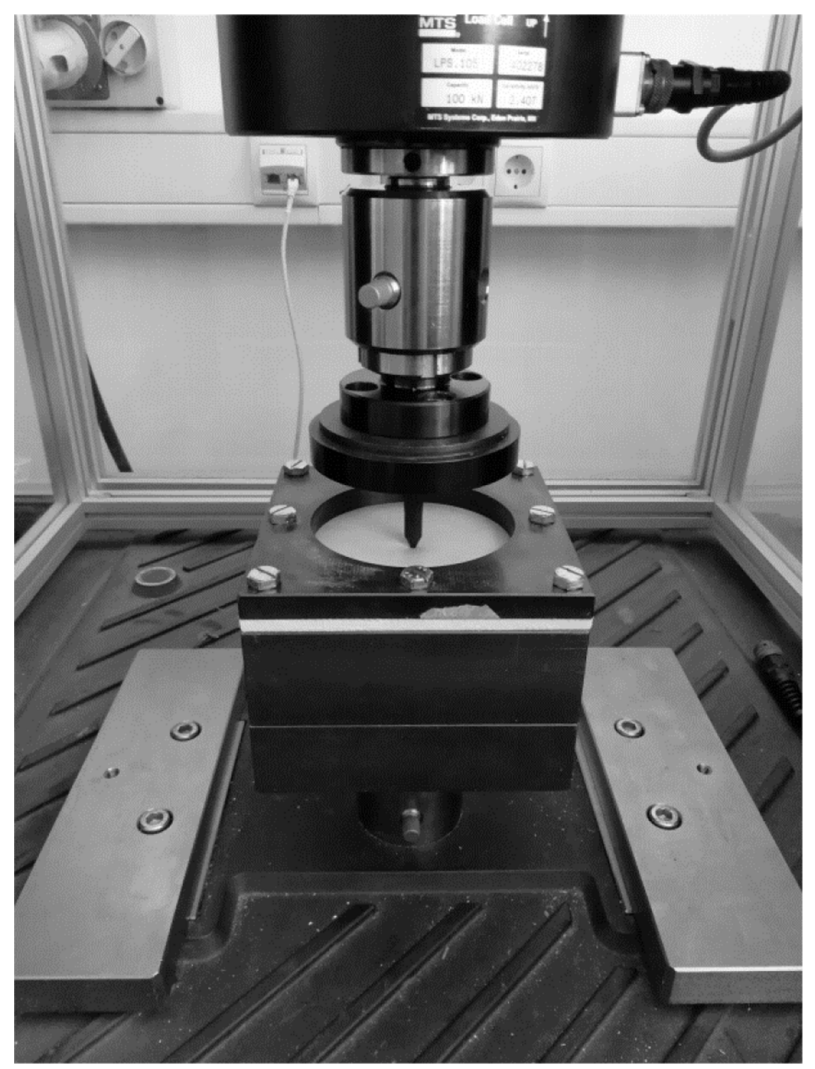

Figure 9: Punch test setup. 


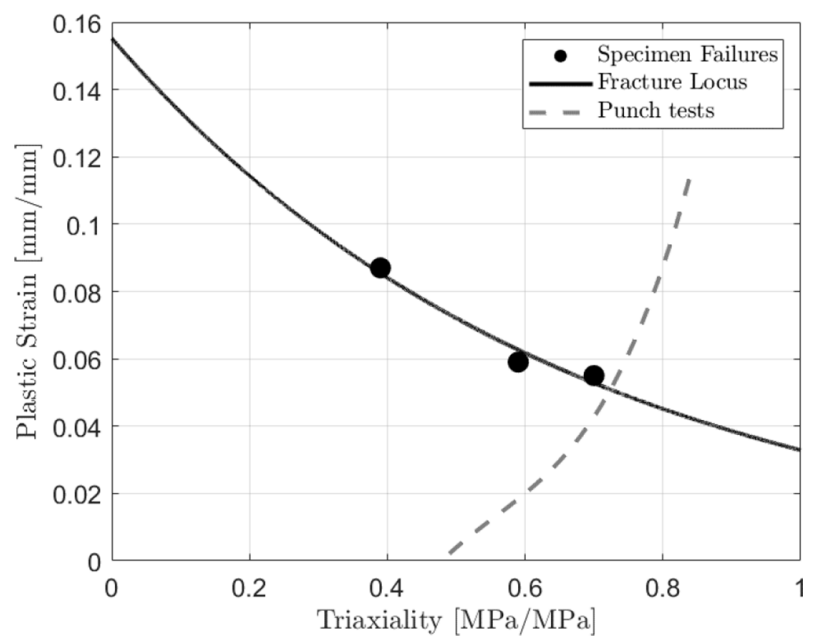

Figure 10: Fracture locus of the aluminum alloy.

$41.202 \mathrm{kN}$ after the punch penetrated the lamina for $6.9 \mathrm{~mm}$. One transient simulation was performed increasing gradually the load from 0 to $50 \mathrm{kN}$. The critical combination of triaxiality-plastic strain was found in correspondence of $40.05 \mathrm{kN}$.

In Fig. 10, the Rice and Tracey calibrated model and validation on the punch test are reported. The dashed line represents the interpolation of the different points associated to simulations with different loads. The points below the curve are the combination of plastic strain and stress triaxiality for which failure did not occur. They correspond to loads below 40 $\mathrm{kN}$. The region above the curve is associated to loads greater than $40 \mathrm{kN}$, where the lamina broke. The first point above the curve is associated with a load of $40.05 \mathrm{kN}$ and a deformation of the lamina of $7.1 \mathrm{~mm}$.

In Table 3, the comparison between experimental and numerical results are reported.

As it can be noticed, the simulations' results are comparable with the experimental findings and confirm the capability of the calibrated model to predict failure in a real test case.

In Fig. 11, the results of the simulations at the failure timestep are shown. The plastic strain and the triaxiality contours are reported. The punch moves vertically toward the lamina. Contact regions are established at the interface between the punch and the lamina. It can be noticed that all the deformation is located in the center region of the lamina, while the deformation tends to zero in the radial direction from the contact. Failure occurs, both according to the experimental evidence and to the numerical predictions, in the middle of the specimen as a consequence of the punch penetration that causes high stresses and strains in the lamina. Cracks starting from the center of the lamina are the origin of the fracture of the component.

Table 3: Experimental vs numerical results.

\begin{tabular}{lllll}
\hline & $\begin{array}{l}\text { Experimental } \\
\text { Load [kN] }\end{array}$ & $\begin{array}{l}\text { Numerical } \\
\text { Load [kN] }\end{array}$ & $\begin{array}{l}\text { Experimental } \\
\text { Displacement [mm] }\end{array}$ & $\begin{array}{l}\text { Numerical } \\
\text { Displacement [mm] }\end{array}$ \\
\hline $\begin{array}{l}\text { Values at } \\
\text { failure }\end{array}$ & 41.202 & 40.050 & 6.9 & 7.1 \\
\hline
\end{tabular}




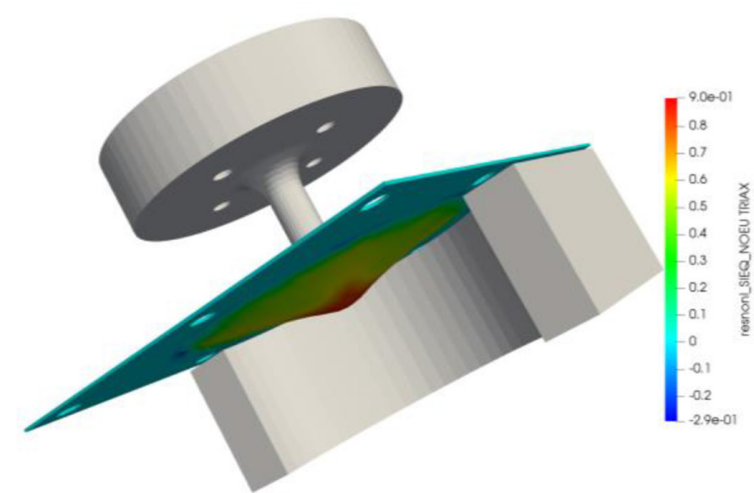

a)

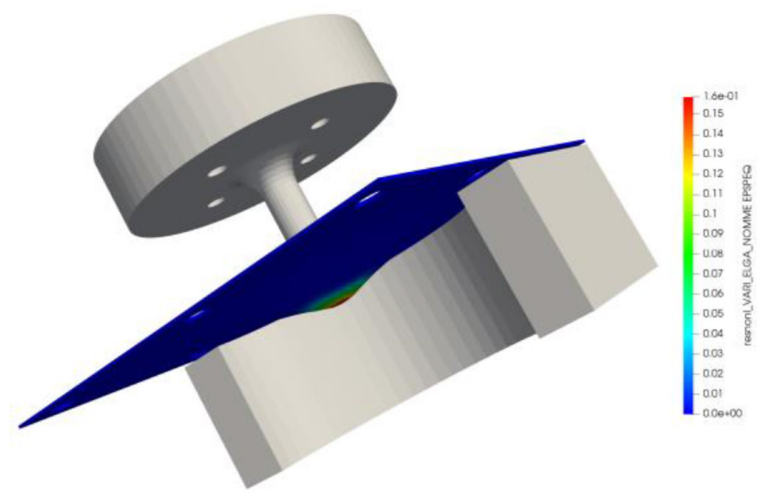

b)

Figure 11: a-b) $\eta$ and $\varepsilon_{p e e q}$ at fracture.

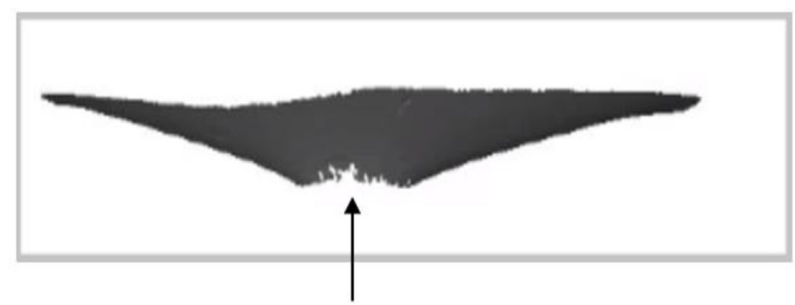

Fracture area

Figure 12: 3D reconstruction of the lamina after failure.

In Fig. 12, the section view of the 3D reconstruction of the broken lamina is shown. The optical 3D scanner ATOS Core from GOM was used to reconstruct the shape of the specimen exploiting a reverse engineering technique that allowed to obtain the detailed shape of the fracture mode with high density of points. The reconstructed model can then be used to deeply analyze the failure shape and to measure deformation of the lamina. The scanner exploits the blue light technology that filters the interferences coming from the ambient light and reduces the acquisition time. It can be observed that the failure mode is the same predicted by the simulation (fracture occurs in the middle of the lamina). This suggests that the 
implemented numerical model can accurately predict the real behavior of the lamina under the punch test.

\section{CONCLUSIONS}

In this paper, the constitutive law of an AlSi10 alloy was calibrated by means of a combined experimental-numerical approach. The Rice and Tracey damage model was applied to a punch test to assess the precision of the calibration process. The numerical results agree well with experimental observations, suggesting good accuracy of the conducted procedure. The authors maintain that further investigations are necessary to increase the tuning of the model. In fact, other tests (e.g. torsional tests) can induce different states of stress in the material, thus providing different points on the curve also at lower values of triaxiality. Moreover, the Lode parameters have increased its importance in the description of failure mechanism of ductile materials and should therefore be considered together with the triaxiality and the equivalent plastic strain in the calibration of the fracture locus.

\section{REFERENCES}

[1] Bridgman, P.W., Studies in Large Plastic Flow and Fracture. Harvard University Press, 1964.

[2] Rice, J.R. \& Tracey, D.M., On the ductile enlagrgement of voids in triaxial stress fields. Journal of the Mechanics and Physics of Solid, 17, p. 201, 1969, https://doi. org/10.1016/j.engstruct.2017.10.075

[3] Mackenzie, A.C., Hancock, J.W. \& Brown, D.K., On the influence of state of stress on ductile failure initiation in high strength steels. Engineering Fracture Mechanics, 9, pp. 167-188, 1977.

[4] Johnson, G.R. \& Cook, W.H., Fracture characteristics of three metals subjected to various strains, strain rates, temperatures and pressures. Engineering Fracture Mechanics, 21(1), pp. 31-48, 1985, https://doi.org/10.1016/0013-7944(85)90052-9

[5] Bao, Y. \& Wierzbicki, T., On fracture locus in the equivalent strain and stress triaxiality space. International Journal of Mechanical Sciences, 46, pp. 81-98, 2004. https://doi. org/10.1016/j.ijmecsci.2004.02.006

[6] Wierzbicki, T., Bao, Y., Lee, Y.W. \& Bai, Y., Calibration and evaluation of seven fracture models. International Journal of Mechanical Sciences, 47(4-5), SPEC. ISS., pp. 719-743, 2005, https://doi.org/10.1016/j.ijmecsci.2005.03.003

[7] Barsoum, I., Faleskog, J. \& Pingle, S., The effect of stress state on ductility in the moderate stress triaxiality regime of medium and high strength steels. International Journal of Mechanical Sciences, 65, pp. 203-212, 2012. https://doi.org/10.1016/j. ijmecsci.2012.10.003

[8] Graham, S., Zhang, T., Gao, X. \& Hayden, M., Development of a combined tensiontorsion experiment for calibration of ductile fracture models under conditions of low triaxiality. International Journal of Mechanical Sciences, 54, pp. 172-181, 2012. https://doi.org/10.1016/j.ijmecsci.2011.10.007

[9] Brünig, M., Chyra, O., Albrect, D., Driemeier, L. \& Alvers, M., A ductile damage criterion at various stress triaxialities. International Journal of Plasticity, 24(10), pp. 17311755, 2009. https://doi.org/10.1016/j.ijplas.2007.12.001

[10] Papasidero, J., Doquet, V. \& Mohr, D., Determination of the effect of stress state on the onset of ductile fracture through tension-torsion experiments. Experimental Mechanics, 54, pp. 137-151, 2014, https://doi.org/10.1007/s11340-013-9788-4 
[11] Cortese, L., Nalli, F. \& Rossi, M., A nonlinear model for ductile damage accumulation under multiaxial non-proportional loading conditions. International Journal of Plasticity, 85, pp. 77-92, 2016, https://doi.org/10.1016/j.ijplas.2016.07.003

[12] Cortese, L., Coppola, T., Campanelli, F., Campana, F. \& Sasso, M., Prediction of ductile failure in materials for onshore and offshore pipeline applications. International Journal of Damage Mechanics, 23(1), pp. 104-123, 2014, https://doi. org/10.1177/1056789513485967

[13] Bonora, N., A nonlinear CDM model for ductile failure. Engineering Fracture Mechanics, 58(1/2), pp. 11-28, 1997, https://doi.org/10.1016/S0013-7944(97)00074-X

[14] Benzerga, A., Surovik, D. \& Keralavarma, S., On the path-dependence of the fracture locus in ductile materials - analysis. International Journal of Plasticity, 37, pp. 157-170, 2012. https://doi.org/10.1016/j.ijplas.2012.05.003

[15] Mae, H., Teng, X., Bai, Y. \& Wierzbicki, T., Calibration of ductile fracture properties of a cast aluminum alloy. Materials Science and Engineering: A, 459(1-2), pp. 156-166, 2007, https://doi.org/10.1016/j.msea.2007.01.047

[16] Xue, Z., Pontin, M., Zok, F.W. \& Hutchinson, J.W., Calibration procedures for a computational model of ductile fracture. Engineering Fracture Mechanics, 77, pp. 492-509, 2010. https://doi.org/10.1016/j.engfracmech.2009.10.007

[17] Ghajar, R., Mirone, G. \& Keshavarz, A., Sensitivity Analysis on triaxiality factor and Lode angle in ductile fracture. Journal of Mechanics, 29, pp. 177-184, 2013. https:// doi.org/10.1017/jmech.2012.125

[18] Mirone, G., Barbagallo, R. \& Corallo, D., A new yield criteria including the effect of lode angle and stress triaxiality. Procedia Structural Integrity, 2, pp. 3684-3696, 2016. https://doi.org/10.1016/j.prostr.2016.06.458

[19] Concli, F. \& Maccioni, L., Experimental-numerical calibration of the fracture locus of a weathering steel. WIT Transactions on Engineering Sciences, 124, pp. 219-227, 2019, https://doi.org/10.2495/MC190211

[20] Concli, F. \& Gilioli, A., Numerical and experimental assessment of the static behavior of 3D printed reticular Al structures produced by selective laser melting: Progressive damage and failure. Procedia Structural Integrity, pp. 204-212, 2018, https://doi. org/10.1016/j.prostr.2018.11.094

[21] Concli, F., Gilioli, A. \& Nalli, F., Experimental-numerical assessment of ductile failure of additive manufacturing selective laser melting reticular structures made of $\mathrm{Al}$ A357. Proceedings of the Institution of Mechanical Engineers, Part C: Journal of Mechanical Engineering Science, p. 095440621983233, March 2019, https://doi. org/10.1177/0954406219832333

[22] Fraccaroli, L., Mastrone, M.N. \& Concli, F., Calibration of the fracture locus of an AlSi10 alluminum alloy. WIT Transactions on The Built Environment, 196, pp. 3-10, 2020. https://doi.org/10.2495/HPSM200011

[23] Gilioli, A., Manes, A., Giglio, M. \& Wierzbicki, T., Predicting ballistic impact failure of aluminium 6061-T6 with the rate-independent Bao-Wierzbicki fracture model. International Journal of Impact Engineering, 76, pp. 207-220, 2015. https://doi.org/10.1016/j. ijimpeng.2014.10.004

[24] Xue, L. \& Wierzbicki, T., Ductile fracture characterization of aluminum alloy 2024t351 using damage plasticity theory. International Journal of Applied Mechanics, 1(2), pp. 267-304, 2009. https://doi.org/10.1142/s1758825109000198 